\title{
Characterization and antioxidant activity of the volatile oils of Thymus Syriacus Boiss. var syriacus and Thymbra spicata L. grown wild in Kurdistan-Iraq
}

\author{
D. M. Jamil ${ }^{1}$, J. E. Brown ${ }^{1}$, D. Driscoll ${ }^{2}$ and N. K. Howell ${ }^{1}$ \\ ${ }^{1}$ Division of Nutritional Sciences and ${ }^{2}$ Division of Chemical Sciences, Faculty of Health and Medical Sciences, \\ University of Surrey, Guildford GU2 7XH, Surrey, UK
}

Herbs and their essential oils are known for their antimicrobial and antioxidant properties in biological systems ${ }^{(1,2)}$. Thyme $($ Thymus syriacus Boiss. var syriacus) and thymbra (Thymbra spicata L.) grow wild in Kurdistan-Iraq and because of their abundance in the region and use in foods their volatile oils (VO) were extracted by hydro-distillation ${ }^{(3)}$, chemically characterised (by GC and GC-MS) and evaluated for their antioxidant activities (using the $\mathrm{Cu}^{2+}$-mediated LDL oxidation method ${ }^{(4,5)}$ ). The kinetics of LDL oxidation was monitored by the change in absorbance of conjugated dienes $(234 \mathrm{~nm})$ over time $(14 \mathrm{~h})$ at $30^{\circ} \mathrm{C}$. The antioxidant efficacy of the VO of each herb and their major and minor terpen(oid)s were measured by their ability to extend the lag phase of oxidation $v$. control ${ }^{(4,5)}$

The VO yield of thymbra and thyme was significantly higher (4.15 (SD 0.15) \% and 3.75 (SD 0.10) \%) in samples grown at higher altitudes $(1100 \mathrm{~m}$ and $900 \mathrm{~m})$ compared with those grown at lower altitudes $(670 \mathrm{~m}$ and $400 \mathrm{~m} ;(2.72$ (SD 0.08$) \%$ and 2.52 (SD 0.12$) \%$ respectively; $P<0.05)$. The principal components identified in the VO of thyme and thymbra are shown in Table 1 . Clear differences were observed for their terpen(oid) content, with the main difference observed in the content of thymol and carvacrol, although the level of $\gamma$-terpinene was also much higher in thymbra. Altitude had little effect on VO composition.

Table 1. Major terpen(oid) identified in thyme and thymbra $(n 6)$

\begin{tabular}{|c|c|c|c|c|c|c|c|c|c|c|c|c|c|c|}
\hline \multirow[b]{2}{*}{ Herbs } & \multicolumn{2}{|c|}{ Thymol } & \multicolumn{2}{|c|}{ Carvacrol } & \multicolumn{2}{|c|}{$P$-cymene } & \multicolumn{2}{|c|}{ Borneol } & \multicolumn{2}{|c|}{$\gamma$-Terpinene } & \multicolumn{2}{|c|}{$\beta$-Caryophyllene } & \multicolumn{2}{|c|}{$\alpha$-Terpinene } \\
\hline & Mean & SD & Mean & SD & Mean & SD & Mean & SD & Mean & SD & Mean & SD & Mean & SD \\
\hline Thymus syriacus & 74.1 & 2.2 & 9 & 1.5 & 5.3 & 0.2 & 2.4 & 0.3 & 2 & 0.3 & 1.7 & 0.2 & 0.7 & 0.1 \\
\hline Thymbra spicata & 0.2 & 0.1 & 74.0 & 3.5 & 7.5 & 0.25 & 0.2 & 0.1 & 10.7 & 1.1 & 1.6 & 0.1 & 1.5 & 0.3 \\
\hline
\end{tabular}

The VO of thyme and thymbra showed clear antioxidant activity by extending lag phase by 43 and $49 \%$ respectively at $1 \mu \mathrm{M}$ (Table 2 ). Pure samples of thymol and carvacrol were shown to be more effective than thyme and thymbra VO by an order of $>10$-fold. The other pure standards tested however were less efficacious. The effectiveness of the compounds tested as antioxidants in this system were thymol $>$ carvacrol $>\gamma$-terpinene $>\alpha$-terpinene $>$ borneol $>\beta$-caryophyllene. Interestingly, $\alpha$-pinene, myrcene and $p$-cymene were found to be pro-oxidant at the concentrations tested.

Table 2. Effects of thyme and thymbra VO and synthetic terpenoids on extending lag phase to oxidation of copper-mediated LDL oxidation (\% increase compared with control oxidation; control lag phase 151 (SD 12) min)

\begin{tabular}{|c|c|c|c|c|c|c|c|c|c|c|c|c|c|c|}
\hline \multirow{2}{*}{$\begin{array}{l}\text { VO or terpenoid } \\
\text { concentration }(\mu \mathrm{m}) \ldots\end{array}$} & \multicolumn{2}{|c|}{0.025} & \multicolumn{2}{|c|}{0.05} & \multicolumn{2}{|c|}{0.1} & \multicolumn{2}{|c|}{0.25} & \multicolumn{2}{|c|}{0.5} & \multicolumn{2}{|c|}{1.0} & \multicolumn{2}{|c|}{2.0} \\
\hline & Mean & SD & Mean & SD & Mean & SD & $\overline{\text { Mean }}$ & $\mathrm{SD}$ & Mean & SD & $\overline{\text { Mean }}$ & $\mathrm{SD}$ & $\overline{\text { Mean }}$ & SD \\
\hline Thyme VO & \multicolumn{2}{|c|}{ ND } & & & & & 40 & 10 & 58 & 24 & 82 & 30 & 96 & 27 \\
\hline Thymbra VO & & & & & & & 34 & 12 & 57 & 14 & 78 & 22 & 117 & 26 \\
\hline Thymol & & & & & & & 262 & 46 & & & & & & \\
\hline Carvacrol & 78 & 3 & 112 & 10 & 172 & 9 & 70 & 9 & & & & & & \\
\hline$\gamma$-Terpinene & 20 & 3 & 38 & 7 & 39 & 13 & 18 & 3 & 27 & 2 & 40 & 3 & 68 & \\
\hline$\alpha$-Terpinene & & & & & & & 12 & 1 & 15 & 1 & 23 & 1 & 32 & \\
\hline Borneol* & & & & & & & & & & & & & & \\
\hline$\beta$-Caryophyllene* & & & & & & & & & & & & & & \\
\hline
\end{tabular}

*Means for two determinations.

These findings may have important implications for the more general use of these herbs in foods.

1. Yanishlivea NV, Marinova E \& Pokorny J (2006) Eur J Lipid Sci Technol 108, 776-793.

2. Lee SJ, Umano K, Shibamoto T et al. (2005) Food Chem. 91, 131-137.

3. Hanci S, Sahin S \& Ylmaz L (2003) Nahrung 47, 252-255.

4. Esterbauer H, Gebicki J, Puhl H et al. (1992) Free Radic Biol Med 13, 341-390.

5. Brown JE \& Kelly MF (2007) Eur J Lipid Sci Technol 109, 66-71. 